Proceedings

\title{
Comparison of Microwave Vacuum Drying with Traditional Rice Bran Stabilization Methods: Impact on Extracted Oil Quality ${ }^{\dagger}$
}

\author{
Mary Michelle Velasquez and Casiana Blanca Villarino*
}

Citation: Velasquez, M.M.; Villarino, C.B.J. Comparison of Microwave Vacuum Drying with Traditional Rice Bran Stabilization Methods: Impact on Extracted Oil Quality. Proceedings 2021, 70, 35. https:// doi.org/10.3390/foods_2020-07729

Published: 10 November 2020

Publisher's Note: MDPI stays neutral with regard to jurisdictional claims in published maps and institutional affiliations.

Copyright: (ㅇ 2020 by the authors. Licensee MDPI, Basel, Switzerland. This article is an open access article distributed under the terms and conditions of the Creative Commons Attribution (CC BY) license (http://creativecommons.org/licenses/by/4.0/).
Department of Food Science and Nutrition, College of Home Economics, University of the Philippines Diliman, Quezon City 1101, Philippines; michelle_velasquez13@yahoo.com

* Correspondence: bjvillarino@up.edu.ph

+ Presented at the 1st International Electronic Conference on Food Science and Functional Foods, 10-25 November 2020; Available online: https://foods_2020.sciforum.net/.

\begin{abstract}
Rice bran requires a stabilization process to prevent the rapid development of rancidity upon rice milling. Common stabilization methods usually take a long time or are harsh, which lead to a decrease in rice bran quality (e.g., nutritional and sensory properties). Microwave vacuum drying is a potential stabilization method for rice bran that generates heat at a lower temperature and allows rapid mass and energy transfer leading to an increased drying rate, thus retaining quality. This study aimed to evaluate the effects of various stabilization methods, i.e., dry heating (DH), microwave heating (MH), vacuum drying (VD) and microwave vacuum drying (MVD), on the quality and antioxidant properties of rice bran oils. It was observed that VD and MVD resulted in better rice bran color retention. Oil extraction yield was significantly increased by MVD and DH compared to unstabilized rice bran. Stabilization of rice bran by MVD, DH and MH resulted in significantly lower free fatty acid content and peroxide values in extracted oils. Total antioxidant capacity and percentage of scavenging activities of rice bran oil samples, as determined using DPPH (2,2-diphenyl-1-picrylhydrazyl) and ABTS (2,2-azino-bis(3-ethylbenzothiazoline-6-sulfonic acid)) assays, were not significantly different. These results suggest that MVD is an efficient rice bran stabilization method that provides similar oil qualities to those produced using traditional stabilization methods.
\end{abstract}

Keywords: rice bran; rice bran oil; stabilization; microwave vacuum drying; microwave heating; vacuum drying; dry heating

\section{Introduction}

Rice bran oil contains high concentrations of bioactive compounds, such as $\gamma$-oryzanol, tocopherols, tocotrienols and phytosterols that have anti-cancer and antioxidant properties and cholesterol-lowering effects on serum [1]. Despite being a valuable byproduct of the rice industry, rice bran is usually discarded as waste or used as a feed supplement for livestock, due to its rapid degradation from hydrolytic and oxidative rancidity caused by lipolytic enzymes [2]. In order to ensure the recovery and production of edible grade oil, rice bran is subjected to stabilization methods for the inactivation of lipolytic enzymes.

Dry heating is an inexpensive method, but it may damage the bran due to a severe and long period of heating [3]. Microwave heating has a shorter duration of treatment; however, the non-uniform distribution of energy during microwave heating may cause adverse effects on the properties of a food product, such as charring [4]. In contrast, vacuum drying allows heat transfer at a lower temperature than atmospheric conditions, but it takes a longer time, resulting in high energy costs [5]. Microwave vacuum drying is a potential stabilization method for rice bran that utilizes microwave radiation in a vacuum 
environment to generate heat at a lower temperature and to allow rapid mass and energy transfer for an increased drying rate [6]. It prevents thermal degradation and improves the sensory, nutritional and functional properties of food products better than the traditional heating methods [7]. However, there is a lack of information on the use of microwave vacuum drying on the stabilization of rice bran and the effects of the stabilization process on the properties and bioactive components of rice bran oils. In this study, the effects of various stabilization methods, i.e., dry heating (DH), microwave heating $(\mathrm{MH})$, vacuum drying (VD) and microwave vacuum drying (MVD), on important quality parameters of rice bran (i.e., moisture content and color) and extracted rice bran oil (i.e., oil yield, free fatty acid content, peroxide value and antioxidant capacity) were investigated.

\section{Materials and Methods}

\subsection{Materials}

Freshly milled rice bran was obtained from a local rice miller in Bulacan, Philippines. The samples were sieved immediately using a Standard Test Sieve No. 45 (WS Tyler, Mentor, $\mathrm{OH}, \mathrm{USA}$ ) to screen unwanted filth and to obtain a uniform particle size of less than $350 \mu \mathrm{m}$. The sieved samples were collected in zip-lock plastic bags and stored in a chesttype freezer (Sanyo Electric Co., Osaka, Japan) at $-20^{\circ} \mathrm{C}$ until stabilization.

\subsection{Stabilization of Rice Bran}

The sieved rice bran samples were divided into five- 5-kg lots. The first lot served as the control, while the remaining lots (i.e., four lots) were stabilized through the different heat treatments described below, in duplicate.

For dry heating (DH), approximately $500 \mathrm{~g}$ of each sample was placed into aluminum trays and spread uniformly in layers of about $0.5 \mathrm{~cm}$ thickness. The trays were dried for $30 \mathrm{~min}$ in a hot air oven (Weber Electric Oven, Philadelphia, PA, USA) maintained at 100 ${ }^{\circ} \mathrm{C}$ [8]. Microwave heating (MH) was done according to the modified method of Ramezanzadeh et al. [9]. The moisture content was adjusted through the addition of deionized water (i.e., 20:3 w/v bran-to-water ratio) to prevent charring. An amount of $500 \mathrm{~g}$ of rice bran was placed in a cylindrical propylene container and heated in a microwave oven (Model X2-20ES Whirlpool, Benton Harbor, MI, USA) set at $720 \mathrm{~W}$ for $6.7 \mathrm{~min}$.

Vacuum drying (VD) followed the modified method of Association of Official Analytical Chemists (AOAC) [10]. Approximately $500 \mathrm{~g}$ of rice bran was spread evenly to a thickness of about $0.5 \mathrm{~cm}$ in aluminum trays. The samples were dried for $5 \mathrm{~h}$ in a vacuum oven (Hinotek, Ningbo, Zheijang, China) set at $65^{\circ} \mathrm{C}$ and $30 \mathrm{~mm} \mathrm{Hg}$. Microwave vacuum drying (MVD) was done using the microwave vacuum dryer designed and developed by Metals Industry Research and Development Center (MIRDC), Department of Science and Technology, Philippines. Sieved rice bran (549 g) was stabilized under $992 \mathrm{~W}$ microwave power, $20 \mathrm{kPa}$ vacuum pressure and 75 rotation speed for $24.66 \mathrm{~min}$ [11].

All stabilized rice bran samples were placed in zip-lock polyethylene bags upon cooling to room temperature and stored in a freezer at $-20^{\circ} \mathrm{C}$ until further use.

\subsection{Moisture Analysis}

The moisture content of the rice bran samples was measured using a rapid moisture analyzer (Uni Bloc MOC63u, Shimadzu, Kyoto, Japan). Approximately $2 \mathrm{~g}$ of rice bran was placed on the sample pan for drying to a stable weight. Results were expressed as $\%$ dry basis.

\subsection{Color Analysis}

The color of the rice bran samples was evaluated using a colorimeter (Model Colorflex E2, Hunterlab Inc., Reston Virginia, VA, USA). Lightness $\left(L^{*}\right)$, redness $\left(+a^{*}\right)$ or greenness $\left(-a^{*}\right)$, and yellowness $\left(+b^{*}\right)$ or blueness $\left(-b^{*}\right)$ were measured. Color difference $(\Delta \mathrm{E})$ 
between the control and the stabilized rice bran samples was also calculated from the $L^{*}$, $a^{*}$, and $b^{*}$ values using the following equation [12]:

$$
\Delta E=\sqrt{\left(L_{f}^{*}-L_{i}^{*}\right)^{2}+\left(a_{f}^{*}-a_{i}^{*}\right)^{2}+\left(b_{f}^{*}-b_{i}^{*}\right)^{2}}
$$

where $i$ is the value of unstabilized rice bran and $f$ represents the value of rice bran after stabilization.

\subsection{Oil Extraction Yield Determination}

The extraction of crude rice bran oil was done according to the modified method of Wang et al. [13]. An amount of $20 \mathrm{~g}$ of rice bran was added with hexane in a 1:3 w/v branto-hexane ratio and stirred at $1150 \mathrm{rpm}$ for $1 \mathrm{~h}$ at room temperature, followed by centrifugation (Hermle Z206 A, HERMLE Labortechnik GmbH, Wehingen, Germany) at 6000 rpm for $30 \mathrm{~min}$. After extraction, the oil miscella was separated through vacuum filtration (Model JP-90H-9, Kawake Airvac Co., Ltd., Hsin Chuang, Taipei, Taiwan). The extract was concentrated using a rotary evaporator (Model IKA RV 10 Digital, Guangzhou, China) at $40{ }^{\circ} \mathrm{C}$ for $10 \mathrm{~min}$ under a reduced pressure. The oil extraction yield was defined as percent $(\%) \mathrm{g}$ oil $/ \mathrm{g}$ rice bran.

\subsection{Oil Quality Analysis}

The free fatty acid (FFA) content and peroxide value (PV) of extracted rice bran oils were determined according to the methods described by Chia et al. [14].

The determination of antioxidant capacity using ABTS (2,2-azino-bis(3-ethylbenzothiazoline-6-sulfonic acid)) assay was based on the modified methods of MartysiakZurowska and Wenta, and Thaipong et al. [15,16]. Equal volumes of stock solutions of 7.4 $\mathrm{mM}$ ABTS + solution and $2.6 \mathrm{mM}$ potassium persulfate $\left(\mathrm{K}_{2} \mathrm{SO}_{4}\right)$ solution were mixed and incubated for $12 \mathrm{~h}$ under dark conditions at room temperature $\left(25^{\circ} \mathrm{C}\right)$. One $\mathrm{mL}$ of the ABTS + solution was diluted with $60 \mathrm{~mL}$ methanol to prepare the fresh ABTS + solution. An absorbance of $0.676 \pm 0.02$ units at $734 \mathrm{~nm}$ was obtained using a single beam UV-Vis Spectrophotometer (LI 295, Lasany International, Haryana, India). For sample analysis, $200 \mu \mathrm{L}$ of rice bran oil was mixed with $3800 \mu \mathrm{L}$ of the ABTS + working solution. The mixture was kept in the dark for $10 \mathrm{~min}$ at room temperature $\left(25^{\circ} \mathrm{C}\right)$ until the absorbance was measured at $734 \mathrm{~nm}$. A calibration curve was prepared using varying concentrations of Trolox standard, ranging from $25-800 \mu \mathrm{M}$, and methanol was used as a blank.

For the DPPH (2,2-diphenyl-1-picrylhydrazyl) assay, a modified method of Thaipong et al. [16] was used. The stock solution was prepared by dissolving $24 \mathrm{mg}$ of DPPH with $100 \mathrm{~mL}$ methanol and was stored at $4{ }^{\circ} \mathrm{C}$ under dark conditions until use. The working solution was prepared by mixing $10 \mathrm{~mL}$ stock solution with $45 \mathrm{~mL}$ methanol. The resulting solution was diluted further with methanol to obtain an absorbance of $1.077 \pm 0.02$ units at $515 \mathrm{~nm}$ using a single beam UV-Vis Spectrophotometer. For the sample analysis, 200 $\mu \mathrm{L}$ of rice bran oil was mixed with $3800 \mu \mathrm{L}$ of DPPH solution. Absorbance was measured at $515 \mathrm{~nm}$ after $24 \mathrm{~h}$ of incubation under dark conditions at room temperature $\left(25^{\circ} \mathrm{C}\right)$. A calibration curve was obtained using varying concentrations $(25-800 \mu \mathrm{M})$ of Trolox standard, and methanol was used as a blank.

Results from the ABTS and DPPH assays were expressed in mg Trolox equivalents (TE)/g oil, and percent scavenging activity (\%SA) was calculated as follows:

$\%$ Scavenging activity $=\frac{\text { Absorbance ABTS/DPPH blank }- \text { Absorbance sample }}{\text { Absorbance ABTS/DPPH blank }} \times 100 \%$

\subsection{Statistical Analysis}

All samples were assessed in duplicate. One-way analysis of variance (ANOVA) was used to compare treatment means, followed by Duncan's multiple range test for mean 
separation when F was significant. Mean separation of unstabilized (control) and stabilized rice bran was carried out with Dunnett's test. All statistical tests were performed using SPSS software version 17 (SPSS Inc., Chicago, IL, USA) at an alpha level of 0.05.

\section{Results}

\subsection{Effect of Stabilization Method on Moisture Content and Color of Rice Bran}

All the stabilization methods significantly lowered $(p<0.05)$ the moisture content of the rice bran samples, except those stabilized with MH (Table 1). For the color of rice bran, it was observed that the rice bran samples stabilized with $\mathrm{MH}$ and $\mathrm{DH}$ showed the highest color difference $(\Delta E)$ values while the lowest VD- and MVD-stabilized samples had the lowest $\Delta E$ values (Table 1 ).

Table 1. Effects of stabilization methods on moisture content and color of rice bran.

\begin{tabular}{|c|c|c|c|c|c|}
\hline \multirow{2}{*}{$\begin{array}{l}\text { Stabilization } \\
\text { Method }^{2}\end{array}$} & \multirow{2}{*}{ 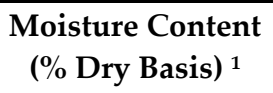 } & \multicolumn{4}{|c|}{ Color 1} \\
\hline & & $L^{*}$ & $a^{*}$ & $b^{*}$ & $\Delta E$ \\
\hline MVD & $8.43^{b *} \pm 0.27$ & $70.58^{c^{*}} \pm 0.09$ & $3.30^{a^{*}} \pm 0.03$ & $20.59^{a} \pm 0.02$ & $1.94^{\mathrm{ab}} \pm 1.61$ \\
\hline $\mathrm{MH}$ & $13.03^{\mathrm{c}} \pm 1.14$ & $68.66^{a^{*}} \pm 0.40$ & $4.18^{c^{*}} \pm 0.22$ & $23.00^{c *} \pm 0.11$ & $4.76^{c} \pm 1.84$ \\
\hline VD & $9.04^{b *} \pm 0.11$ & $71.92^{\mathrm{d}} \pm 0.79$ & $3.15^{\mathrm{a}} \pm 0.05$ & $20.36^{\mathrm{a}} \pm 0.22$ & $0.67^{\mathrm{a}} \pm 0.64$ \\
\hline $\mathrm{DH}$ & $2.77^{a^{*}} \pm 0.44$ & $69.91^{b *} \pm 0.37$ & $3.71^{b *} \pm 0.15$ & $22.24^{b *} \pm 0.49$ & $3.39 b c \pm 0.83$ \\
\hline Unstabilized & $13.58 \pm 0.47$ & $72.45 \pm 1.45$ & $3.09 \pm 0.11$ & $20.14 \pm 0.51$ & - \\
\hline
\end{tabular}

${ }^{1}$ Mean \pm standard deviation. ${ }^{2}$ MVD, microwave vacuum drying; $\mathrm{MH}$, microwave heating; VD, vacuum drying; DH, dry heating. abc Values with different superscripts within the same column denote significant difference $(p<0.05)$ using Duncan's test. ${ }^{*}$ Denotes significant difference $(p<0.05)$ from unstabilized rice bran using Dunnett's test.

\subsection{Effect of Stabilization Method on Extraction Yield and Quality of Rice Bran Oil}

The oil extraction yield of MH- and VD-stabilized rice bran samples had no significant difference $(p<0.05)$ from the unstabilized rice bran (Table 2$)$. The highest oil extraction yield was noted from the rice bran samples with MVD and DH treatment. Oil extracts from rice bran samples stabilized by MVD, DH and MH showed significantly lower $(p<$ 0.05) FFA content and PV as compared to those of unstabilized rice bran oil.

Table 2. Effects of stabilization methods on extraction yield, FFA and PV of rice bran oil.

\begin{tabular}{|c|c|c|c|}
\hline Stabilization Method ${ }^{2}$ & Oil Extraction Yield (\%) ${ }^{1}$ & $\begin{array}{c}\text { FFA } \\
(\% \text { Oleic Acid })^{1} \\
\end{array}$ & $\begin{array}{c}\text { PV } \\
(\mathrm{mEq} / \mathrm{kg} \text { Oil })^{1}\end{array}$ \\
\hline MVD & $9.34^{c^{*}} \pm 0.64$ & $11.15^{\mathrm{a}^{*}} \pm 0.94$ & $12.28^{a^{*}} \pm 0.64$ \\
\hline $\mathrm{MH}$ & $7.74^{\mathrm{a}} \pm 0.35$ & $13.71^{b *} \pm 1.25$ & $15.33^{\mathrm{b} *} \pm 1.21$ \\
\hline VD & $8.53^{b} \pm 0.66$ & $17.01^{\mathrm{c}} \pm 1.77$ & $18.92^{\mathrm{c}} \pm 0.90$ \\
\hline $\mathrm{DH}$ & $8.744^{b *} \pm 0.68$ & $12.05^{a *} \pm 1.03$ & $14.73^{b *} \pm 0.90$ \\
\hline Unstabilized & $7.71 \pm 0.60$ & $17.44 \pm 2.03$ & $19.49 \pm 1.07$ \\
\hline
\end{tabular}

${ }^{1}$ Mean \pm standard deviation. ${ }^{2}$ MVD, microwave vacuum drying; $\mathrm{MH}$, microwave heating; VD, vacuum drying; $\mathrm{DH}$, dry heating. abc Values with different superscripts within the same column denote significant difference $(p<0.05)$ using Duncan's test. ${ }^{*}$ Denotes significant difference $(p<0.05)$ from unstabilized rice bran using Dunnett's test.

Results showed that there are no significant interaction effects $(p<0.05)$ between the total antioxidant capacity (TAC) and \% scavenging activity of oils from different rice bran samples (Table 3). 
Table 3. Effects of stabilization methods on the antioxidant capacity of rice bran oil.

\begin{tabular}{|c|c|c|c|c|}
\hline \multirow{2}{*}{$\begin{array}{l}\text { Stabilization } \\
\text { Method }^{2}\end{array}$} & \multicolumn{2}{|c|}{ DPPH Assay ${ }^{1}$} & \multicolumn{2}{|c|}{ ABTS Assay $^{1}$} \\
\hline & $\begin{array}{c}\text { TE }^{3} \\
(\mathrm{mg} \mathrm{TE} / 100 \mathrm{~g} \text { Oil) ns, ** }\end{array}$ & $\underset{\mathrm{ns}, * *}{\% \text { Scavenging Activity }}$ & $\begin{array}{c}\mathrm{TE}^{3} \\
\left(\mathrm{mg} \mathrm{TE} / 100 \mathrm{~g} \mathrm{Oil}^{\mathrm{ns}, * *}\right.\end{array}$ & $\underset{\mathrm{ns}, * *}{\% \text { Scavenging Activity }}$ \\
\hline MVD & $188.45 \pm 3.24$ & $76.85 \pm 1.32$ & $87.74 \pm 5.98$ & $76.36 \pm 5.46$ \\
\hline $\mathrm{MH}$ & $184.20 \pm 4.92$ & $75.45 \pm 2.00$ & $91.65 \pm 5.03$ & $79.92 \pm 4.59$ \\
\hline VD & $187.82 \pm 3.51$ & $76.64 \pm 1.43$ & $92.84 \pm 3.70$ & $81.01 \pm 3.37$ \\
\hline $\mathrm{DH}$ & $187.36 \pm 3.82$ & $76.45 \pm 1.55$ & $90.72 \pm 3.21$ & $79.07 \pm 2.93$ \\
\hline Unstabilized & $184.58 \pm 2.57$ & $75.32 \pm 1.05$ & $91.62 \pm 2.67$ & $79.89 \pm 2.43$ \\
\hline
\end{tabular}

${ }^{1}$ Mean \pm standard deviation. ${ }^{2}$ MVD, microwave vacuum drying; MH, microwave heating; VD, vacuum drying; DH, dry heating. ${ }^{3} \mathrm{TE}-$ Trolox equivalent. ${ }^{n s}$ Denotes no significant difference $(p<0.05)$ between stabilization methods using Duncan's test. $^{* *}$ Denotes no significant difference $(p<0.05)$ between stabilization methods and unstabilized rice bran using Dunnett's test.

\section{Discussion}

\subsection{Effect of stabilization Method on Moisture Content and Color of Rice Bran}

Stabilization by MH did not cause an appreciable reduction in moisture content when compared with the unstabilized rice bran, possibly because of the addition of water to the bran prior to heating in order to prevent charring. Rice bran contains moderately high amounts of reducing sugars and proteins that may induce Maillard reactions during heating [17]. The greater extent of browning during the $\mathrm{MH}$ and $\mathrm{DH}$ stabilization may be attributed to elevated temperatures during drying. On the other hand, the effect of reduced pressure on VD and MVD, consequently lowering the temperature, possibly slowed down the occurrence of Maillard reactions in the bran.

\subsection{Effect of Stabilization Method on Extraction Yield and Quality of Rice Bran Oil}

The vaporization of moisture during drying causes the rice bran to become brittle, which may lead to greater rupture of tissue and facilitate the oil extraction process [18]. However, the lipid extraction efficiency of hexane on samples stabilized by MH may have been affected by the high amount of moisture present in the bran, as hexane is insoluble in water [19]. In the case of $\mathrm{VD}$, it is possible that the low drying temperature may have created a lesser degree of tissue rupture in the bran, resulting in low solvent permeability on the cell membrane during oil extraction. On the other hand, MVD allowed faster mass transfer of moisture to the surface, which possibly led to increased porosity and enhanced solvent extraction. Moreover, the improved oil extraction yield by DH may be attributed to the modification of the cell wall structure during drying and minimized interference of moisture on the solvent extraction process.

The lowest FFA content and PV were observed in the oil extracts from rice bran samples stabilized by MVD, DH and MH, suggesting that these stabilization methods were effective in suppressing lipolytic activity in rice bran. Moreover, the lower FFA content and PV of oils with MVD treatment may be due to the absence of air during drying, preventing oxidation reactions during the drying process as compared to the high temperature drying by $\mathrm{DH}$ and $\mathrm{MH}$. In addition, the rapid decrease of moisture hindered degradation reactions in MVD-stabilized rice bran. These results are in agreement with Park et al., who reported that MVD of brown rice resulted in lower fatty acid content than with MH alone [12]. Stabilization by VD did not result in considerably lower FFA content and PV than the unstabilized samples, even with the absence of air, but the low drying temperature may not be adequate to cause the inactivation of lipolytic enzymes in the bran. This may have been exacerbated by a longer time to stabilize the rice bran, allowing for the enzymatic reactions to occur during the stabilization process.

Results showed that the use of different stabilization methods had no influence on the TAC and \% SA of the extracted rice bran oil samples. Although stabilization methods can reduce the loss of antioxidants by inhibiting the activity of lipolytic enzymes, heating 
might decompose thermolabile bioactive components in the rice bran [20]. The TAC and $\%$ SA of the oil extracted from the unstabilized rice bran were comparable with those of the oils from the stabilized samples, possibly because no heat treatment was applied, resulting in preservation of heat-sensitive compounds.

\section{Conclusions}

Rice bran was successfully stabilized by MVD, resulting in rice bran and rice bran oils comparable to the quality of those stabilized using traditional methods. MVD shows potential in stabilizing rice for good quality oil. Further studies on the bioactive compounds of rice bran oil are needed to verify the effects of stabilization methods on the antioxidant properties of oils.

Author Contributions: Conceptualization, C.B.V. and M.M.V.; methodology, C.B.V. and M.M.V.; formal analysis, M.M.V.; writing - original draft preparation, M.M.V.; writing - review and editing, C.B.V. and M.M.V. All authors have read and agreed to the published version of the manuscript.

Funding: This research was supported by the Office of the Vice President for Academic AffairsUniversity of the Philippines, under the Enhanced Creative Work and Research Grant (ECWRG).

Institutional Review Board Statement: Not applicable.

Informed Consent Statement: Not applicable.

Data Availability Statement: Data is contained within the article.

Conflicts of Interest: The authors declare no conflict of interest.

\section{References}

1. Liang, Y.; Gao, Y.; Lin, Q.; Luo, F.; Wu, W.; Lu, Q.; Liu, Y. A review of the research progress on the bioactive ingredients and physiological activities of rice bran oil. Eur. Food Res. Technol. 2014, 238, 169-176.

2. Bureau of Agricultural Research. Available online: http://www.bar.gov.ph/index.php/chronicle-home/archives-list/148-april2008-issue/2124-promising-potentials-of-rice-bran-explored (accessed on 22 February 2017).

3. Sansak, S.; Jongyingcharoen, J.S. Effect of hot air assisted infrared drying on drying characteristics and quality of rice bran pellets. MATEC Web Conf. 2018, 192, 03040.

4. Ibrahim, G.E.; El-Ghorab, A.H.; Osman, F.; El-Massry, K.F. Effect of microwave heating on flavour generation and food processing. In The Development and Application of Microwave Heating; Cao, W., Ed.; In Tech: Rijeka, Croatia, 2012; pp. 17-44.

5. Ratti, C. Freeze and vacuum drying of foods. In Drying Technologies in Food Processing; Chen, X.D., Mujumdar, A.S., Ed.; Blackwell Publishing Ltd.: Oxford, UK, 2008; pp. 225-253.

6. Scaman, C.H.; Durance, T.D.; Drummond, L.; Sun, D.-W. Combined microwave vacuum drying. In Emerging Technologies for Food Processing, 2nd ed.; Sun, D.-W., Ed.; Academic Press: Cambridge, MA, USA, 2014; pp. 427-445.

7. Bondaruk, J.; Markowski, M.; Błaszczak, W. Effect of drying conditions on the quality of vacuum-microwave dried potato cubes. J. Food Eng. 2007, 81, 306-312.

8. Sharma, H.R.; Chauhan, G.S.; Agrawal, K. Physico-chemical characteristics of rice bran processed by dry heating and extrusion cooking. Int. J. Food Prop. 2004, 7, 603-614.

9. Ramezanzadeh, F.M.; Rao, R.M.; Windhauser, M.; Prinyawiwatkul, W.; Marshall, W.E.; Tulley, R. Prevention of hydrolytic rancidity in rice bran during storage. J. Agric. Food Chem. 1999, 47, 3050-3052.

10. AOAC. Official Methods of Analysis, 17th ed.; Association of Official Analytical Chemists: Washington, DC, USA, 2000.

11. Villarino, C.B.J.; Azanza, M.P.; Ramos, H.J.; Rogelio, J.P.; Soriano, J.K.; Obile, M.V.; Abulencia, G.L. Effects of microwave vacuum drying on the quality and stability of rice bran: Response 1 surface modelling and on-site verification. Unpublished.

12. Park, I.; Park, J.; Lee, H.; Kum, J. Effects of air, microwave, and microvacuum drying on brown rice quality. J. Korean Soc. Appl. Biol. Chem. 2012, 55, 523-528.

13. Wang, M.; Hettiarachchy, N.S.; Qi, M.; Burks, W.; Siebenmorgen, T. Preparation and functional properties of rice bran protein isolate. J. Agri. Food Chem. 1999, 47, 411-416.

14. Chia, S.; Boo, H.; Muhamad, K.; Sulaiman, R.; Umanan, F.; Chong, G. Effect of subcritical carbon dioxide extraction and bran stabilization methods on rice bran oil. J. Am. Oil Chem. Soc. 2015, 92, 393-402.

15. Martysiak-Żurowska, D.; Wenta, W. A comparison of ABTS and DPPH methods for assessing the total antioxidant capacity of human milk. Acta Sci. Pol. Technol. Aliment. 2012, 1, 83-89.

16. Thaipong, K.; Boonprakob, U.; Crosby, K.; Cisneros-Zevallos, L.; Byrne, D. Comparison of ABTS, DPPH, FRAP, and ORAC assays for estimating antioxidant activity from guava fruit extracts. J. Food Compos. Anal. 2006, 19, $669-675$. 
17. Lamberts, L.; Brijs, K.; Mohamed, R.; Verhelst, N.; Delcour, J.A. Impact of browning reactions and bran pigments on color of parboiled rice. J. Agric. Food Chem. 2006, 54, 9924-9929.

18. Thanonkaew, A.; Wongyai, S.; McClements, D.J.; Decker, E.A. Effect of stabilization of rice bran by domestic heating on mechanical extraction yield, quality, and antioxidant properties of cold-pressed rice bran oil (Oryza sativa L.). LWT Food Sci. Technol. 2012, 48, 231-236.

19. Efthymiopoulos, I.; Hellier, P.; Ladommatos, N.; Kay, A.; Mills Lamptey, B. Effect of solvent extraction parameters on the recovery of oil from spent coffee grounds for biofuel production. Waste Biomass Valor 2019, 10, 253-264.

20. Godber, J.S. Oil from rice and maize. In Encyclopedia of Food Grains, 2nd ed.; Wrigley, C., Corke, H., Seetharaman, K., Faubion, J., Eds.; Elsevier Ltd.: Oxford, UK, 2016; Volume 3, pp. 453-457. 